\title{
Retrospective review of the clinical case of a radical correction of the transposition of the great vessels, complicated by mediasthenitis and sepsis
}

Rackhima Mekenbayeva ${ }^{1}$, Shukhrat Marassulovi ${ }^{1}$, Amangeldy Kerimkulovi, Baurzhan Tuyakbayev ${ }^{1}$, Anar Sarsembayeva $^{1}$, Timur Sarsengaliyev ${ }^{2}$, Raushangul Nygymanbekova ${ }^{3}$, Nigina Mekenbayeva ${ }^{4}$, Arman Akseitov $^{4}$

${ }^{1}$ Pediatric Cardiac Surgery Department, National Scientific Medical Center, Nur-Sultan city, Republic of Kazakhstan

${ }^{2}$ Radiodiagnosis Department, National Scientific Medical Center, Nur-Sultan city, Republic of Kazakhstan ${ }^{3}$ Cardiology Department, National Scientific Medical Center, Nur-Sultan city, Republic of Kazakhstan

${ }^{4}$ Astana Medical University, Nur-Sultan city, Republic of Kazakhstan

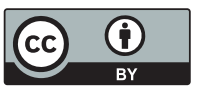

This work is licensed under a Creative Commons Attribution 4.0 International License

Received: 2019-02-28

Accepted: 2019-04-18

UDC: 616.1

J Clin Med Kaz 2019; 2(52):59-62

Corresponding Author: Rackhima Mekenbayeva, Pediatric Cardiac Surgery Department, National Scientific Medical Center. Address: 7\1, Mailin street, 010001 Nur-Sultan city, Republic of Kazakhstan.

Tel: +7 705 485-75-81

E-mail: mrt.14@mail.ru

\section{Abstract}

In the century of advanced technology, medicine has leaped forward, which contributed to the possibility of correcting such severe congenital heart defects in children as the transposition of great vessels. However, despite the progress in medicine and compliance with the rules of asepsis and antisepsis, infection of the postoperative wound remains one of the frequent and terrible postoperative complications, worsening the prognosis and increasing the risk of mortality. In this retrospective analysis, we consider a clinical case of a radical correction of the great vessels transposition with a complication that has arisen (wound infection) in the early and late postoperative period. The relevance of the article lies in the fact that we studied international experience in managing patients with this complication and applied it in this clinical case in a child with transposition of great vessels, who underwent several cardiac and thoracic operations complicated by wound infection, sepsis, DIC-syndrome with significant deficit bone skeleton of the chest. The child's condition improved significantly: infectious complications were stopped, signs of heart failure decreased. The child is observed for 7 years, the observation will continue.

Key words: congenital heart defect, great vessels transposition, open arterial duct, interatrial septum defect, interventricular septum defect

\section{ЖУРЕК ІРІ ТАМЫРЛАРЫНЫН ОРЫН АУЫСУЫ ТУА БІТКЕН АҚАУЫНЫН ТУБЕГЕЙЛІ ТҮЗЕТУІНЕН КЕЙІН МЕДИАСТЕНИТ ЖӘНЕ СЕПСИСПЕН АСҚЫНҒАН КЛИНИКАЛЫҚ ЖАҒДАЙЫН РЕТРОСПЕКТИВТІ ШОЛУ}

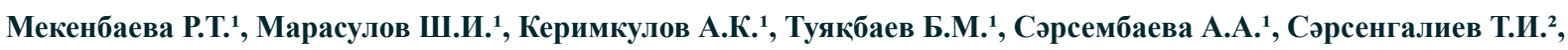
Нығыманбекова P.М. ${ }^{3}$, Мекенбаева Н.Б. ${ }^{4}$, Ақсеитов А.М. ${ }^{4}$

'Балалар кардиохирургия бөлімі, Ұлттық ғылыми медициналық орталық, Нұр-Сұлтан қаласы, Қазақстан Республикасы

${ }^{2}$ Сәулелі диагностика бөлімі, Ұлттық ғылыми медициналық орталық, Нұр-Сұлтан қаласы, Қазақстан Республикасы

${ }^{3}$ Кардиология бөлімшесі, Ұлттық ғылыми медициналық орталық, Нұр-Сұлтан қаласы, Қазақстан Республикасы

${ }^{4}$ Астана медициналық университеті, Нұр-Сұлтан қаласы, Қазақстан Республикасы

\section{тҰЖЫРЫМДАМА}

Озық технологиялар ғасырында медицина айтарлықтай алға жылжыды, бұл жүрек ірі тамырланыңың ауысуы сияқты туа біткен ақауларын емдеуге мүмкіндік тудырды. Дегенмен, медицинадағы жетістіктерге, асептикалық және антисептикалық ережелерді сақтауға қарамастан, операциядан кейінгі жараға инфекция жұқтыру қорқынышы операциядан кейінгі асқынулардың бірі болып қала береді, осы жағдай болжамды нашарлатады және өлім қаупін арттырады. Осы ретроспективті талдауда жүректің ірі тамырларының орын ауысуына радикалдық коррекция жасалғаны және операциядан кейін пайда болған асқыну (жараның инфекциялануы) клиникалық жағдайы қарастырылады. Мақаланың маңыздылығы - осындай жағдаймен науқастарды емдеудегі халықаралық тәжірибені зерделеп, жүректің ірі тамырлары ауысқан, бірнеше кардиохирургиялық және кардиоторакалды операция жасалған, жараның инфекцияланауы, сепсис, ДВСсиндромы, кеуде сүйектерінің жетіспеушілігімен асқынған балаға қолдандық. Баланың жағдайы айтарлықтай жақсарды: инфекциялы асқынулар тоқтатылды, жүрек жетіспеушілік белгілері азайды. Бала 7 жыл бойы бақылауда болды және бақылау жалғасады.

Негізгі сөздер: туа біткен жүрек кемістігі, ірі тамырларының транспозициясы, ашық артериялық түтік, жүрекшелер аралық қалқаның кемістігі, қарыншалар аралық қалқаның кемістігі 
РЕТРОСПЕКТИВНЫЙ ОБЗОР КЛИНИЧЕСКОГО СЛУЧАЯ ПОСЛЕ РАДИКАЛЬНОЙ КОРРЕКЦИИ ТРАНСПОЗИЦИИ МАГИСТРАЛЬНЫХ СОСУДОВ, ОСЛОЖНЕННОЙ МЕДИАСТЕНИТОМ И СЕПСИСОМ.

Мекенбаева Р.Т. ${ }^{1}$, Марасулов Ш.И. ${ }^{1}$, Керимкулов А.К. ${ }^{1}$, Туякбаев Б.М. ${ }^{1}$, Сарсенбаева А.А. ${ }^{1}$, Сарсенгалиев Т.И. ${ }^{2}$,

Нығыманбекова Р.М. ${ }^{3}$, Мекенбаева Н.Б. ${ }^{4}$, Аксеитов А.М. ${ }^{4}$

'Детское кардиохирургическое отделение, Национальный научный медицинский центр, город Нур-Султан, Республика Казахстан

${ }^{2}$ Отделение лучевой диагностики, Национальный научный медицинский центр, город Нур-Султан, Республика Казахстан

${ }^{3}$ Отделение кардиологии, Национальный научный медицинский центр, город Нур-Султан, Республика Казахстан

${ }^{4}$ Медицинский университет Астана, город Нур-Султан, Республика Казахстан

\section{РЕЗЮМЕ}

В век развитых технологий медицина шагнула вперед, что способствовало возможности коррекции таких тяжелых врожденных пороков сердца у детей, как транспозиция магистральных сосудов. Однако, несмотря на прогресс в медицине и соблюдение правил асептики и антисептики, инфицирование послеоперационной раны остается одним из частых и грозных послеоперационных осложнений, ухудшающих прогноз и увеличивающих риск летальности. В данном ретроспективном анализе рассмотрен клинический случай радикальной коррекции транспозиции магистральных сосудов с возникшим осложнением (инфицирование раны) в раннем и позднем послеоперационном периоде. Актуальность статьи заключается в том, что мы изучили международный опыт в ведении пациентов с таким осложнением и применили его в данном клиническом случае у ребенка с транспозицией магистральных сосудов, которому было проведено несколько кардиохирургических и торакальных операций, осложненных инфицированием раны, сепсисом, ДВС-синдромом со значимым дефицитом костного скелета грудной клетки. Состояние ребенка значительно улучшилось: инфекционные осложнения купированы, признаки сердечной недостаточности уменьшились. Ребенок наблюдается в течение 7 лет, наблюдение будет продолжено.

Ключевые слова: врожденный порок сердца, транспозиция магистральных сосудов, открытый артериальный проток, дефект межпредсердной перегородки, дефект межжелудочковой перегородки.

\section{Актуальность}

Транспозиция магистральных сосудов (ТМС) врожденный порок сердца, анатомическим субстратом которого является аномальное расположение аорты и легочной артерии относительно друг друга и их обратное отхождение от желудочков сердца. Средняя частота встречаемости транспозицией магистральных сосудов среди различных врожденных пороков сердца (ВПС) составляет $7-15 \%$, в 3 раза чаще встречается у мальчиков [1].

Физиологической особенностью транспозиции магистральных сосудов является то, что сатурация кислорода в стволе легочной артерии выше, чем в аорте изза наличия двух параллельных кругов кровообращений. Для жизнеобеспечения пациента с ТМС необходимо смешивание крови из параллельных кругов кровообращения, которое возможно через открытый артериальный проток (ОАП), либо через сопутствующие дефекты межжелудочковой (ДМЖП) или межпредсердной перегородки (ДМПП). В случаях сочетания ТМС с ДМЖП или ДМПП очень быстро развивается легочная гипертензия, которая может привести к летальному исходу уже к концу первого года жизни [2].

Поэтому, для предупреждения закрытия ОАП при подтверждении диагноза ТМС в первые дни жизни ребенка проводится постоянная инфузия вазопростана (простагландина Е1). Это особенно важно при ТМС с ДМЖП и обструкцией выводного тракта левого желудочка (ОВТЛЖ). У новорожденных с выраженной гипоксемией во время катетеризации сердца необходимо проведение баллонной атриосептостомии Рашкинда. Эффективность данной процедуры оценивается по повышению сатурации на $10 \%$ и более, отсутствию метаболического ацидоза, а также по увеличению потока через межпредсердное сообщение, появлению флотирующих кра $е в$ перегородки в области отверстия и изменению относительных разме $\neg$ ров предсердий [3].

Следует отметить, что активное применение простагландинов в условиях малого межпредсердного сообщения может быть опасным. Это связано с тем, что большой сброс через ОАП, приводящий к уве-ллиенному возврату крови из легких в левоепредсердие, сопровожда $е т с я ~$ неадекватным опорожнением последнего и чревато развитием оте ᄀка легких.

Эндоваскулярная баллонная атриосептостомия (процедура Рашкинда) применяется в случае абсолютных противопоказаний по сопутствующей патологии как паллиативный метод хирургического лечения и как метод стабилизации состояния ребенка перед радикальной операцией.

Данная процедура показана при следующей патологии:

- $\mathrm{TMC} \mathrm{с} \mathrm{интактной} \mathrm{межжелудочковой} \mathrm{перегородкой}$ (ИМЖП);

- ТМС в сочетании с ДМЖП или ОАП.

Виды хирургической коррекции:

Одноэтапная коррекция

- ТМС с интактной МЖП - операция артериального переключения;

- ТМС с ДМЖП - операция артериального переключения + пластика дефекта заплатой из аутоперикарда/ ксеноперикарда/синтетической заплатой;

- ТМС с ДМЖП и стенозом легочной артерии (ЛА) операция Растелли, REV, операция Никайдо

- ТМС с ОВТЛЖ (КоА, перерыв дуги аорты)реконструкция дуги аорты с артериальным переключением.

Двухэтапная коррекция включает в себя:

Сужение легочной артерии (операция Мюллера, бандинг) в сочетании с наложением модифицированного системно-легочного анастомоза/атриосептостомии показано при инволюции миокарда ЛЖ в целях подготовки ЛЖ для дальнейшей системной циркуляции.

Причины отсрочки операции для артериального переключения:

- возраст старше 4-8 недель, если давление в ЛЖ составляет менее $66 \%$ от системного давления, отношение массы левого желудочка к массе правого желудочка $<0,6$;

- пациенты с ТМА с ИМЖП в возрасте до 3 недель с гипоплазией левого желудочка;

- некротический энтероколит;

- почечная и печеночная недостаточность;

- кровоизлияние в мозг;

- сепсис, недоношенность с очень малой массой ребенка;

- ожидаемое спонтанное закрытие ДМЖП;

- поздняя постановка диагноза;

- после неудачной коррекции ТМС на уровне предсердий (после операций предсердного переключения по методам Мастарда или Сеннинга).

Во всех вышеперечисленных случаях можно сделать 
выбор между первичной коррекцией гемодинамики на предсердном уровне и двухэтапной хирургической коррекцией. При выборе тактики ведения пациента можно использовать эхокардиографические показатели (наличие или отсутствие выбухания межжелудочковой перегородки в полость левого желудочка, толщина стенки, объем желудочка), как критерии диагностики [4].

Несмотря на успешное проведение коррекции порока и применение профилактической антибактериальной терапии возможно развитие инфекционных осложнений, таких как “инфицирование послеоперационной раны”.

Проблема инфицированных ран грудной стенки является актуальной для современной кардиохирургии. При проведении сложных и агрессивных операций используют торакальный доступ с рассечением грудины - срединную стернотомию, что увеличивает послеоперационные инфекционные риски.

По данным Бураковского В.И. (1988), Измайлова Г.А. и соавт. (1998), Бирюкова Ю.В. и соавт. (1990), Вишневского АЛ. и соавт. (1994), Плечева В.В. и соавт. (2003), Loop F.D. etal (1984), Yean J.S. etal. (1985) у 0,4 - 7\% пациентов, перенёсших срединную стернотомию, наблюдаются послеоперационные инфекционные осложнения.

Инфекционные осложнения после проведения операций на сердце с использованием срединной стернотомии дают летальность до 44\% (SerryCetal 1985). Особую опасность представляет собой острый медиастинит, развивающийся в первые дни после оперативного вмешательства, когда послеоперационная рана наиболее восприимчива к инфицированию. Распространение процесса в области средостения может вызывать развитие эрозивных кровотечений.

\section{Описание случая}

В данном ретроспективном обзоре клинического случая представлено течение послеоперационного периода при инфицировании операционной раны после коррекции ТМС.

Пациент С., возраст - 11 лет, поступил в клинику в плановомпорядке с жалобами на болезненность ипокраснение в области послеоперационной раны, кровотечение из раны.

Из анамнеза заболевания: ТМС диагностирован с рождения. В динамике пациент регулярно наблюдался у кардиолога, кардиохирурга. У пациента в возрасте 9 лет была проведена паллиативная операция - создание дефекта межпредсердной перегородки в условиях ИК. Далее, в возрасте 11 лет пациенту была проведена катетеризация полостей сердца с последующей радикальной коррекцией ТМС (по Растелли): рестернотомия, кардиолиз, формирование внутрисердечного тоннеля между левым желудочком и аортой с помощью заплаты Gore-Tex, формирование сообщения между правым желудочком и левой легочной артерией с помощью кондуита, пластика ДМПП с помощью заплаты Gore-Tex, клипирование ОАП в условиях ИК и глубокой гипотермии. Проводилась массивная антибактериальная терапия. Ребенок был выписан с улучшением под наблюдение специалистов по месту жительства.

Через 2 месяца после радикальной операции пациент поступил в стационар с инфицированием послеоперационной раны, была произведена экстренная ревизия раны и остановка кровотечения из кондуита.

При перевязке: пальпаторно перираневая область безболезненна, в области нижней трети грудины кожный дефект размером 2,0х1,0 см за счет гипертрофированнорубцовых тканей, над резецированным участком грудинно- реберного сочленения имеется раневой канал по ходу кондуита размером 1,5 см, дном которого является гранулирующая ткань с фибриновым налетом, имеется скудное отделяемое зеленовато-желтого цвета, слизистого характера, без запаха.

После консультации микрохирурга была выполнена операция по устранению дефекта покровных тканей передней стенки грудной клетки с ротацией сложносоставного кожножирового и фасциально-мышечного лоскута, транспозиция порции малой грудной мышцы в область дефекта передней стенки грудной клетки. С улучшением ребенок был выписан под наблюдение специалистов по месту жительства.

Через 3 месяца после выписки пациент повторно поступает в клинику по линии санитарной авиации с жалобами на серозно-кровянистое отделяемое из мягких тканей в области операционной раны, локальную боль, эпизоды обильного кровотечения из имеющихся свищей в области послеоперационной раны.

\section{Результаты физикального, лабораторного и инструментального исследования}

При локальном осмотре в области средней трети грудины отмечается наличие 2-х свищей с умеренным кровянистым отделяемым. Около свищевые зоны уплотнены, отмечается отек и гиперемия мягких тканей, серозно-гнойное отделяемое.

По данным ЭХОКГ - фистула кондуита Contegra. В перикарде и плевральных полостях жидкости не выявлено.

По данным микробиологического исследования мазка из зева: Streptococcusviridans 1x10 5КОЕ/мл, чувствительность к меропенему, ванкомицину, гентамицину.

В последующих микробиологических анализах выделен Streptococcuspyogenes 1x105КОЕ/мл, чувствителен к амоксициллину, левофлоксацину, меропенему, ванкомицину, цефазолину, цефуроксиму, цефтриоксону, цефепиму, амикацину, гентамицину.

После предоперационной подготовки больного проведена операция: рестернотомия, кардиолиз, удаление кондуита Contegra междулегочной артерией и правым желудочком, имплантация кондуита GoreTex№20 с моностворкой в условиях ИК, наложение thorax apertum. Неоднократно производились ревизии полости перикарда, отсроченный остеосинтез, установка проточно-промывной системы. Проводилась массивная антибактериальная терапия согласно чувствительности.

После проведенных оперативных вмешательств у ребенка в области послеоперационной раны отмечался дефицит грудины от уровня мечевидного отростка от сочленения 4-го ребра, дефицит хрящевой части 2-3 ребра, дефицит мягких тканей в средней трети грудины.

Пациент консультирован ортопедом-вертебрологом, кем рекомендовано сведение верхней и нижней трети грудины с установкой проточно-промывной системы.П р о в е д е н а операция: закрытие дефекта грудной клетки встречными кожными лоскутами.

После проведения данного оперативного лечения состояние пациента значительно улучшилось. Локально: повязка на грудине сухая, по снятии в области послеоперационного рубца отечности, гиперемии, отделяемого нет.

Контрольные микробиологические исследования показали отсутствие роста бактериальной или грибковой инфекции.

Ребенок выписан с улучшением под наблюдение у кардиолога по месту жительства. Для проведения 
динамического наблюдения регулярно проводится амбулаторное обследование ребенка в условиях нашей клиники.

Последнее амбулаторное обследование проведено в 2018 году в 15-летнем возрасте, которое показало относительно удовлетворительное состояние системы кровообращения после 9 операций в течение 7 лет наблюдения.

\section{Дискуссия}

В заключение, инфицирование раны после кардиохирургических операций является осложнением, которое влияет на показатели смертности, заболеваемости и финансовой эффективности лечения. С целью изучения международного опыта, используемого для профилактики инфицирования раны и применения данных знаний с позиций доказательной медицины мы обратились в англоязычную базу данных медицинских публикаций - PubMed.

Был проведен обширный поиск литературы для оценки вмешательств и профилактики инфицирования послеоперационной раны после кардиохирургических операций. Из 743 найденных статей было отобрано 48 рандомизированных контролируемых испытаний. Эффективными мерами были признаны: антибактериальная профилактическая терапия цефалоспоринами в течение 24 часов после операции, местное применение гентамицина до закрытия грудной клетки, закрытие грудины с помощью нержавеющих стальных проволок [5].
В данном клиническом случае у ребенка с ТМС было проведено несколько кардиохирургических и торакальных операций, осложненных инфицированием раны, сепсисом, ДВС-синдромом со значимым дефицитом костного скелета грудной клетки. Нами использованы данные доказательной медицины по применению цефалоспоринов III-IV поколений для профилактики гнойных осложнений, а также при развитии медиастенита и сепсиса в данном случае были использованы комбинации антибактериальных препаратов разных групп, в томчислеаминогликозиды(системноиместно).Особенностью течения осложнений в клиническом примере является дефицит грудины и 2-х ребер, формирующих переднюю грудную стенку. В данном случае удаление грудины и 2-х ребер было проведено во время первой кардиохирургической операции хирургами из Польши, что вызвало значительные технические затруднения для реабилитации пациента после повторных кардиохирургических операций. Осложнения купированы благодаря рациональной антибактериальной терапии, признаки сердечной недостаточности значительно уменьшились. В настоящее время состояние ребенка удовлетворительное, наблюдение продолжается.

Disclosures: There is no conflict of interest for all authors.

Patient informed consent: obtained.

\section{Литература}

1. Belozerov Ju.M. Detskaya kardiologiya (Children's cardiology) [in Russian]. MEDpress-inform. 2004; 159.

2. Richard A. Jonas. Surgical treatment of congenital heart defects. 2004; 261-267.

3. V.N. Zaporozhan, I.L. Babij, S.R. Galich, et al. Congenital malformations: Practical guide. Odessa:ONMedU. $2012 ; 320$.

4. Surgical treatment of the great vessels transposition in children. Republican Center for Health Development, Ministry of Health of the Republic of Kazakhstan. Clinical protocols of the Ministry of Health of the RK 2015.

5. Vos RJ, Van Putte BP, Kloppenburg GTL. Prevention of deep sternal wound infection in cardiacsurgery, review of literature. $J$ Hosp Infect. 2018; 100(4):411-420 https://doi.org/10.1016/j.jhin.2018.05.026

How to cite this article: Rackhima Mekenbayeva, Shukhrat Marassulov, Amangeldy Kerimkulov, Baurzhan Tuyakbayev, Anar Sarsembayeva, Timur Sarsengaliyev, Raushangul Nygymanbekova, Nigina Mekenbayeva, Arman Akseitov. Retrospective review of the clinical case of a radical correction of the transposition of the great vessels, complicated by mediasthenitis and sepsis [in Russian]. J Clin Med Kaz. 2019; 2(52):59-62 